\title{
Effects of temperature on flood forecasting: analysis of an operative case study in Alpine basins
}

\author{
A. Ceppi ${ }^{1}$, G. Ravazzani ${ }^{1}$, A. Salandin ${ }^{2}$, D. Rabuffetti ${ }^{2}$, A. Montani ${ }^{3}$, E. Borgonovo ${ }^{4}$, and M. Mancini ${ }^{1}$ \\ ${ }^{1}$ Politecnico di Milano - D.I.C.A., Piazza Leonardo da Vinci, 32, 20133 Milan, Italy \\ ${ }^{2}$ A.R.P.A. Piemonte - Via Pio VII 9, 10135 Turin, Italy \\ ${ }^{3}$ ARPA-SIMC (HydroMeteoClimate Regional Service of Emilia-Romagna), Viale Silvani 6, 40122 Bologna, Italy \\ ${ }^{4}$ ELEUSI Research Center Department of Decision Sciences, Bocconi University, Viale Isonzo 25, 20135 Milan, Italy \\ Correspondence to: A. Ceppi (alessandro.ceppi@mail.polimi.it)
}

Received: 23 August 2012 - Published in Nat. Hazards Earth Syst. Sci. Discuss.: -

Revised: 18 February 2013 - Accepted: 27 February 2013 - Published: 19 April 2013

\begin{abstract}
In recent years the interest in the forecast and prevention of natural hazards related to hydro-meteorological events has increased the challenge for numerical weather modelling, in particular for limited area models, to improve the quantitative precipitation forecasts (QPF) for hydrological purposes.

After the encouraging results obtained in the MAP DPHASE Project, we decided to devote further analyses to show recent improvements in the operational use of hydrometeorological chains, and above all to better investigate the key role played by temperature during snowy precipitation.

In this study we present a reanalysis simulation of one meteorological event, which occurred in November 2008 in the Piedmont Region. The attention is focused on the key role of air temperature, which is a crucial feature in determining the partitioning of precipitation in solid and liquid phase, influencing the quantitative discharge forecast (QDF) into the Alpine region. This is linked to the basin ipsographic curve and therefore by the total contributing area related to the snow line of the event.

In order to assess hydrological predictions affected by meteorological forcing, a sensitivity analysis of the model output was carried out to evaluate different simulation scenarios, considering the forecast effects which can radically modify the discharge forecast.

Results show how in real-time systems hydrological forecasters have to consider also the temperature uncertainty in forecasts in order to better understand the snow dynamics and its effect on runoff during a meteorological warning with a crucial snow line over the basin.
\end{abstract}

The hydrological ensemble forecasts are based on the 16 members of the meteorological ensemble system COSMO-LEPS (developed by ARPA-SIMC) based on the non-hydrostatic model COSMO, while the hydrological model used to generate the runoff simulations is the rainfallrunoff distributed FEST-WB model, developed at Politecnico di Milano.

\section{Introduction}

The number of great natural catastrophes is increasing worldwide, as underlined in the last Munich Re report (Munich Re, 2011): since 1980 a total number of 773 natural disasters were mainly caused by meteorological (e.g. severe weather, local storms) and hydrological events (e.g. river floods, landslides) - at $46 \%$ and $28 \%$, respectively. This fact, combined with the increased anthropization of our territories that makes them more vulnerable to climatic and hydrological variability, especially with prolonged and alternating periods of droughts and intense rainfalls, has a strong impact on society with potentially high financial and human losses.

The coupling of meteorological and hydrological models has become one of the most important challenges in the scientific community during the two last decades (Brath and Burlando, 1988; Serban and Askew, 1991; Cloke and Pappenberger, 2009).

Unfortunately, due to the complexity of these models, it is difficult to identify and discriminate uncertainty and error sources that can affect the forecast reliability (Krzysztofowicz, 1999). 
Jaun (2008) summarizes the main sources of uncertainty in three classes: initialization uncertainty, hydrological model uncertainty and uncertainty in meteorological data used to drive the hydrological model; this latter states that "accurate predictions of precipitation amounts and temperature values (for snow related events) are required. These uncertainties are propagated within the hydro-meteorological forecasting system and affect accuracy and reliability of the resulting hydrological prediction".

Hence, in order to come to a rigorous quantification of uncertainty in flood predictions, the hydrological community is looking with increasing interest at ensemble prediction systems (EPS) instead of single (deterministic) forecasts for flood warning. From the hydrological perspective, the use of meteorological EPS as input into hydrological models is an important tool to produce ensemble river discharge forecasts, and to assess uncertainty involved in forecasting precipitation and runoff (Krzysztofowicz, 2001; Pappenberger et al., 2005; Gouweleeuw et al., 2005; Ramos et al., 2007; Jaun et al., 2008; Thielen et al., 2009b; He et al., 2009).

In the last decade, the use of hydro-meteorological chains by international agencies and research centres has become more and more widespread and is also fostered by several scientific projects regarding flood forecast such as EFAS in 2003 (Thielen et al., 2009a; Bartholmes et al., 2009) and HEPEX in 2004 (Schaake et al., 2006; Thielen et al., 2008), among others. Further international programmes dealing with these topics were the following: (1) AMPHORE (Application des Methodologies de Previsions Hydrometeorologiques Orientees aux Risques Environnementaux) in 2006 (Amengual et al., 2008; Rabuffetti et al., 2008), a continuation of the HYDROPTIMET Project (Rabuffetti and Milelli, 2005), mainly devoted to the hydro-meteorological modelling of heavy precipitation events causing floods and the optimization of the existing warning systems in the western Mediterranean Basin; (2) the European COST Action 731 (Propagation of Uncertainty in Advanced MeteoHydrological Forecast System) (Rossa et al., 2010; Zappa et al., 2010); (3) RAPHAEL (Runoff and Atmospheric Process for flood HAzard forEcasting and controL) in 1998 (Bacchi and Ranzi, 2003); (4) the Mesoscale Alpine Programme (MAP) between 1994 and 2005 (Ranzi et al., 2003, 2007); and (5) in 2007 the MAP D-PHASE Project (Demonstration of Probabilistic Hydrological and Atmospheric Simulation of flood Events) - this latter has shown recent improvements in the operational use of an end-to-end forecasting system, consisting of atmospheric models, hydrological prediction systems, nowcasting tools and warnings for end users (Zappa et al., 2008; Arpagaus et al., 2009; Rotach et al., 2009; Ranzi et al., 2009).

In this paper we focus on the relevance of accurate temperature forecasts, which has a crucial role in determining the split-up of precipitation into the solid (snow) or liquid phase (rainfall) over Italian Alpine catchments. This is a topic which has not been extensively investigated in the scientific community (brief mentions in Westrick and Mass, 2001; Weingartner et al., 2003; Verbunt et al., 2007). However, this issue applies for all those regions, especially mountain basins, where the snow line (and the snow dynamics) significantly affects the whole hydro-meteorological forecast during heavy precipitation events in the cold season.

This is demonstrated in this paper for two Italian Alpine catchments (the Toce and Sesia). We show the reliability of a flood forecasting system for a heavy rainfall event which occurred in November 2008 in the Piedmont region (northwest of Italy) in analysing atmospheric forcing errors that can affect river discharge predictions.

Results demonstrate that precipitation is not the only meteorological forcing error to be considered in hydrological forecasts, but temperature errors play a crucial role in runoff forecasts in mountains areas. We then investigate the effects of temperature errors on the peak discharge. We apply the separation factor method for separating the effect of errors in the precipitation and temperature fields, assessing both their individual effect and their interactions.

This study allows better understanding of these effects during a warning meteorological event, especially when the basin snow line becomes a decisive aspect in the surface runoff generation; this depends on the basin ipsographic curve and its contributing area.

\section{The geographic area of this study}

The area of interest is the Piedmont region, located in northwestern Italy. This area is of particular importance because its territory sums up several different morphological and climatic features. In this paper two river basins are analysed: the Toce and Sesia (Fig. 1).

The Toce Basin has an area of $1534 \mathrm{~km}^{2}$ closed at the Candoglia gauging station: $90 \%$ of this mountain watershed is located in Italy, the north-western part in Switzerland. Due to its elevation, extended glacial areas, and yearly rainfall value of about $1400 \mathrm{~mm}$ - most of which is concentrated in the autumn season - it is a basin prone to flash floods, where it has an observed index flood (the mean value of maximum annual flood peak, Bocchiola et al., 2003) of $1090 \mathrm{~m}^{3} \mathrm{~s}^{-1}$, while the yearly average discharge is about $63 \mathrm{~m}^{3} \mathrm{~s}^{-1}$.

The Sesia Basin covers an area of $2606 \mathrm{~km}^{2}$ up to the Palestro gauging station; only $45 \%$ of the basin is in mountain territory. Precipitation (annual average of about $900 \mathrm{~mm}$ over the plain and up to $2000 \mathrm{~mm}$ over mountain) usually falls intensely in the autumn season, when high runoff values are observed. Low soil permeability in the upper watershed area amplifies heavy precipitation impacts; this basin has an index flood of $2063 \mathrm{~m}^{3} \mathrm{~s}^{-1}$, while the yearly average runoff is $82 \mathrm{~m}^{3} \mathrm{~s}^{-1}$;

Regarding these two catchments, daily warning thresholds used by ARPA Piedmont for alert issuing (code 2) and alarm (code 3) are reported in Table 1. They are defined on the basis 

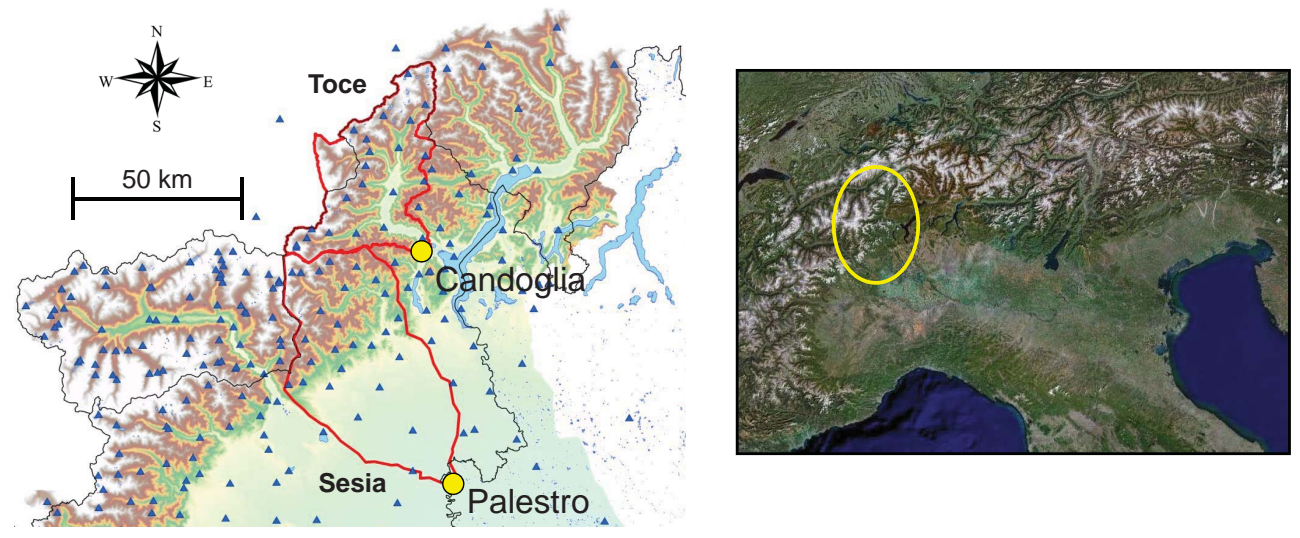

Fig. 1. Digital elevation model (DEM) of the area in the study. On the left side, the boundaries of each basin are shown in bold red, watershed gauging stations are illustrated with yellow dots, and rain gauges in blue triangles.

of the capacity of each cross section and its river branch, and evaluated by means of offline hydraulic analysis and, when available, on the basis of historical flood data (Rabuffetti et al., 2008).

In the Piedmont warning system when the discharge reaches the "code 2" value the flood wave is generally inside the riverbed, but interaction with levees and bridges can cause local dangers; when it reaches the "code 3" value, the flood wave can produce extensive flooding and serious damages to structures along the river, resulting in very hazardous conditions (Rabuffetti et al., 2009).

\section{Models}

\subsection{Coupling strategy}

This section describes the main characteristics of the meteorological and hydrological models used to produce the QDFs (quantitative discharge forecasts) for the November 2008 event.

This system is currently based on hydrological model initialization from meteorological model output, providing river discharge forecasts with some days in advance and obtaining useful time for decision making, emergency management procedures and civil protection.

Four fundamental meteorological fields were extracted: temperature, relative humidity, net solar radiation, and precipitation. Meteorological inputs are interpolated at the spatial resolution of hydrological model using the nearest neighbour method (Voronoi, 1907) that selects the value of the meteorological model nearest to the node.

The hydrological model was initialized with a simulation run forced with observed ground-measured data provided by the Environment Protection Regional Agency of Piedmont hydro-meteorological station network, which uses the same model every day for nowcasting monitoring and as a civil protection tool.
Table 1. Main characteristics of the catchments involved in the analysis.

\begin{tabular}{lccccc}
\hline $\begin{array}{l}\text { Gauging } \\
\text { station }\end{array}$ & River & $\begin{array}{c}\text { Drained } \\
\text { area } \\
{\left[\mathrm{km}^{2}\right]}\end{array}$ & $\begin{array}{c}\text { Lag } \\
\text { time } \\
{[\mathrm{h}]}\end{array}$ & $\begin{array}{c}\text { Alert } \\
\text { code } \\
{\left[\mathrm{m}^{3} \mathrm{~s}^{-1}\right]}\end{array}$ & $\begin{array}{c}\text { Alarm } \\
\text { code } \\
{\left[\mathrm{m}^{3} \mathrm{~s}^{-1}\right]}\end{array}$ \\
\hline $\begin{array}{l}\text { Candoglia } \\
\text { Palestro }\end{array}$ & Toce & 1534 & 9.0 & 1150 & 2100 \\
\hline
\end{tabular}

\subsection{Meteorological model}

The probabilistic forecast was supplied by the COSMOLEPS (Montani et al., 2003; Marsigli et al., 2005; Montani et al., 2011), implemented and developed by ARPA EmiliaRomagna in the framework of the COSMO consortium.

The LEPS methodology allows the combination of the benefits of the probabilistic approach with the highresolution detail of the limited-area-model (LAM) integrations, with a limited computational investment.

The main features of the COSMO-LEPS are the following: a spatial resolution of $10 \mathrm{~km}\left(0.09^{\circ}\right)$ and a temporal resolution of $3 \mathrm{~h}$, with 40 vertical levels and 16 ensembles nested on selected members of the ECMWF EPS (European Centre for Medium-range Weather Forecast - Ensemble Prediction System), and $132 \mathrm{~h}$ as the lead-time; the run starts every day at 12:00 UTC, while the hydrological simulation begins $12 \mathrm{~h}$ later at 00:00 UTC, hence $120 \mathrm{~h}$ of hydrological simulation are available.

\subsection{Hydrological model}

In this study hydrological simulations were performed using the FEST-WB distributed water balance model (Rabuffetti et al., 2008; Ravazzani et al., 2010; Pianosi and Ravazzani, 2010), which has been in development entirely at Politecnico di Milano since 1990 (Mancini, 1990). The model is spatially distributed and physically based, and the acronym stands 
for "Flash flood Event-based Spatially distributed rainfallrunoff Transformations-Water Balance" (FEST-WB).

FEST-WB calculates the main processes of the hydrological cycle: evapotranspiration, infiltration, surface runoff, flow routing, subsurface flow and snow dynamics. The computational domain is discretized with a mesh of regular square cells ( $1 \mathrm{~km}$ in this application), in which water fluxes are calculated at hourly time intervals.

The model requires precipitation, air temperature, air relative humidity, and net solar radiation, sum of short wave and long wave components. The observed data at ground stations are interpolated to a regular grid using the inverse distance weighting technique. Spatial distribution of local air temperature measurements takes into account the reduction of temperature with altitude, with a constant lapse rate of $-0.0065^{\circ} \mathrm{C} \mathrm{m}^{-1}$ (Rabuffetti et al., 2006); thermal inversion phenomena are neglected. In order to facilitate integration with meteorological models, the FEST-WB can also accept spatial gridded meteorological fields as input.

In the FEST-WB model the partitioning of total precipitation, $P$, in liquid, $P_{1}$, and solid, $P_{\mathrm{s}}$, phase is a function of air temperature, $T_{\mathrm{a}}$ (Tarboton et al., 1994):

$$
\begin{aligned}
& P_{1}=\alpha_{p} P \\
& P_{\mathrm{s}}=\left(1-\alpha_{p}\right) P,
\end{aligned}
$$

where $\alpha_{p}$ is calculated as follows:

$$
\alpha_{p}=\left\{\begin{array}{cll}
0 & \text { if } & T_{\mathrm{a}} \leq T_{\text {low }} \\
1 & \text { if } & T_{\mathrm{a}} \geq T_{\text {sup }} \\
\frac{T_{\mathrm{a}}-T_{\text {low }}}{T_{\text {sup }}-T_{\text {low }}} & \text { if } & T_{\text {low }}<T_{\mathrm{a}}<T_{\text {sup }}
\end{array},\right.
$$

where $T_{\text {low }}$ and $T_{\text {sup }}$ are air temperatures below or above which precipitation falls as snow or rain, respectively; in this study, $T_{\text {low }}$ was calibrated at $-3{ }^{\circ} \mathrm{C}$ and $T_{\text {sup }}$ at $+0^{\circ} \mathrm{C}$ (Corbari et al., 2009).

The snow melt simulation is based on the degree day concept (Martinec and Rango, 1986). The melting rate $M_{\mathrm{S}}$ $\left[\mathrm{m} \mathrm{s}^{-1}\right]$ is proportional to the difference between air temperature and a predefined threshold temperature, $T_{\mathrm{b}}$ :

$$
M_{\mathrm{s}}=\left\{\begin{array}{lll}
C_{\mathrm{m}}\left(T_{\mathrm{a}}-T_{\mathrm{b}}\right) & \text { if } & T_{\mathrm{a}}>T_{\mathrm{b}} \\
0 & \text { if } & T_{\mathrm{a}} \leq T_{\mathrm{b}}
\end{array}\right.
$$

where $C_{\mathrm{m}}\left[\mathrm{m}^{\circ} \mathrm{C}^{-1} \mathrm{~s}^{-1}\right]$ is an empirical coefficient, depending on meteorological conditions and geographic location; generally, $C_{\mathrm{m}}$ coefficient ranges from $4.8 \times 10^{-8}$ to $6.9 \times$ $10^{-8} \mathrm{~m}^{\circ} \mathrm{C}^{-1} \mathrm{~s}^{-1}$.

The predefined temperature $T_{\mathrm{b}}$ fixes a threshold beyond which snow starts melting, and its value is usually assumed to be equal to $0^{\circ} \mathrm{C} ; T_{\mathrm{b}}$ and $C_{\mathrm{m}}$ are calibrated values of the model.

For further details upon development of the FEST-WB, the reader can refer to Montaldo et al. (2003, 2007), Ravazzani et al. (2007, 2011), and Ravazzani (2013).

\section{Results and discussion}

In this section we analyse a meteorological event, which occurred in November 2008, concerning the sensitivity of the atmospheric forcing on discharge forecasts.

\subsection{The November 2008 event: the role of atmospheric forcings}

The synoptic analysis over Europe for the period of 1-5 November 2008 shows a cut-off cyclonic circulation over the Mediterranean Sea, originated by a cold-air upper level trough elongated over France and Spain. The associated intense moist and warm southerly flow, impinging over the Alpine chain, caused severe precipitation on the southern side of the Alps.

In the first five days of November 2008, more than $200 \mathrm{~mm}$ (Table 2 and Fig. 2) fell over the Toce and Sesia as mean areal rainfall obtained from the available rain gauges in the two basins (Fig. 1), and a meteorological warning was issued by the regional authority.

The snow line during this event was located between 1700 and $2100 \mathrm{~m}$ a.s.l. on the Alpine area. Thus, forecast temperature played a critical role in discharge prediction in the Toce and Sesia basins. Table 3 summarizes the simulation results obtained with the COSMO-LEPS forecast into the FEST-WB model over the selected basins from lead time 4 (i.e. 96$120 \mathrm{~h}$ before the main peak flow) to one day ahead (lead time 1).

\subsubsection{Sesia River at Palestro}

Due to severe precipitation, an alert code 2 (orange horizontal line in Fig. 3 - right) was issued over the Sesia Basin. The FEST-WB model simulation forced with observed data is affected by an underestimation of discharge (about $20 \%$ ); in fact, the observed value (red line in Fig. 3 - right) at Palestro gauging station is equal to $2025 \mathrm{~m}^{3} \mathrm{~s}^{-1}$, while the simulated discharge by the FEST-WB (green dashed line) is only $1685 \mathrm{~m}^{3} \mathrm{~s}^{-1}$, thereby not exceeding the alert threshold. In Table 3 we show a brief summary of the simulation reanalysis carried out at the beginning of November, with the COSMOLEPS forecasts at different lead times, starting from the initialized run on 1 November 2008 (i.e. $96-120 \mathrm{~h}$ before the main peak flow) to one day ahead (lead time 1).

In particular, only with the simulation starting on 4 November where the forecasted precipitation for 5 November were similar in terms of timing and amount to the observed values (Fig. 3 - left), a correct discharge warning (Fig. 3 - right) was flagged; in fact, the ensemble median forecast exceeded alert code 2 (with a value equal to $2203 \mathrm{~m}^{3} \mathrm{~s}^{-1}$ ), very similar to the measured runoff at Palestro $\left(2025 \mathrm{~m}^{3} \mathrm{~s}^{-1}\right)$. 


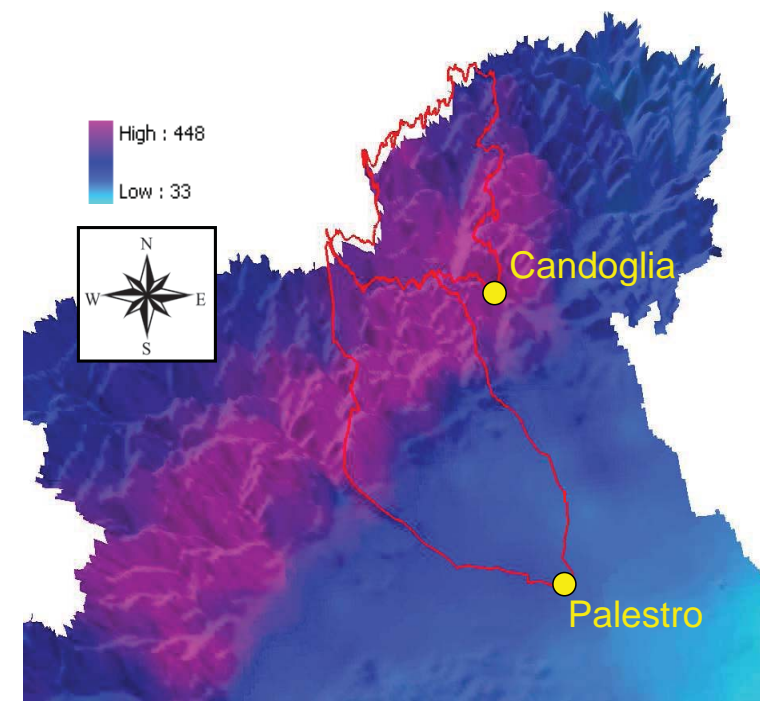

Fig. 2. 3-D map of the precipitation cumulated [in $\mathrm{mm}$ ] between 1 and 5 November 2008 over the Toce and Sesia basins; colours show the quantitative observed precipitation. The digital elevation model of the terrain is shown in 3-D.

\subsubsection{Toce River at Candoglia}

The same analyses were also performed over the Toce Basin, where a different trend was found; the forecast performance worsened approaching the peak event on 5 November. Looking at the predicted QDF over the Toce Basin with the 4 November run, we can immediately note that a false alarm is forecast for 5 November since a possible flood is predicted (Fig. 4 - right).

The ensemble median reached a value of $1841 \mathrm{~m}^{3} \mathrm{~s}^{-1}$, i.e. an overestimation of about $100 \%$ in comparison with the observed value at Candoglia $\left(916 \mathrm{~m}^{3} \mathrm{~s}^{-1}\right)$. Furthermore, the ensemble spread exceeded alert code 2 and the 75 th percentile even exceeded the alarm code 3 ; this resulted in a false alarm that could have caused huge damages.

The FEST-WB simulation forced with observed data (green dashed line) shows a very good match between the measured value at the basin gauging station (red line) in terms of peak discharge $\left(992 \mathrm{~m}^{3} \mathrm{~s}^{-1}\right.$ vs. $\left.916 \mathrm{~m}^{3} \mathrm{~s}^{-1}\right)$, although there is a delay of some hours in terms of timing.

The COSMO-LEPS QPF (quantitative precipitation forecast) agrees with the observation until the first hours of 5 November (Fig. 4 - left). Therefore, it is not a QPF error that produced the remarkable discharge overestimation shown before. If we look at the ensemble spread and median value of predicted rainfall, they are very close to the observed value (at basin scale) in the first $36 \mathrm{~h}$ from the beginning of simulation; this result lead to our consideration of another factor that could have caused the discharge overestimation with the COSMO-LEPS forecast.

Because this event was typical of the autumn season with heavy precipitation over the area and with a snow line at
Table 2. Mean areal precipitation cumulated over the Toce and Sesia basins during the 1-5 November 2008 event.

\begin{tabular}{lrr}
\hline Days & Toce & Sesia \\
\hline 1 November 2008 & 6.5 & 6.8 \\
2 November 2008 & 7.2 & 8.3 \\
3 November 2008 & 52.2 & 38.5 \\
4 November 2008 & 79.0 & 88.8 \\
5 November 2008 & 95.4 & 43.5 \\
\hline Cumulated precipitation [mm] & 240.3 & 185.9 \\
\hline
\end{tabular}

about 1700-2000 m a.s.l., we tried to examine the temperatures predicted by the meteorological model.

Looking at temperature evolution between 4 and 5 November (Fig. 5), corresponding to the most intense precipitation period over the Toce catchments, a large temperature overestimation (on average about $3{ }^{\circ} \mathrm{C}$ ) was observed for COSMOLEPS forecasts. In order to assess the impact of errors in temperature forecasts on QDF, a sensitivity analysis was carried out.

\subsection{Sensitivity analysis at finite changes}

In the following sensitivity analysis, the FEST-WB model was run for alternative combinations of input variables and the corresponding model output simulations were compared.

Our task was to understand "what it was about the inputs that made the outputs come out as they did" (Little, 1970, p. B469). A sensitivity analysis method should make it possible to obtain the following insights:

a. How much does each factor impact the forecast result?

b. What is the direction of change in model response given the factor's change?

c. Do interaction effects amplify or counterbalance individual effects?

d. What is the key driver of the model response?

In order to answer the above questions quantitatively, we utilize a generalization of the factor separation method (Stein and Alpert, 1983). For technical details and a rigorous mathematical derivation, we refer to the works of Efron and Stein (1981), Sobol' (1993), Rabitz and Alis (1999), Borgonovo (2010), and Borgonovo and Peccati (2011).

Some notations first. We allow the following:

- $P=$ precipitation field,

- $T$ = temperature field,

that is, the factors in our case are the entire precipitation and temperature fields, which in turn are constituted by the set of all the corresponding measurements or model data: 
Table 3. Comparison between observed data and simulated peak discharge values $\left[Q\right.$ in $\left.\mathrm{m}^{3} \mathrm{~s}^{-1}\right]$ with the FEST-WB model driven by measured data and the COSMO-LEPS forcings at different lead times; values exceeding alert code 2 are shown in bold. The Q median shows the median value of discharge forecasts at different lead times (hours before the main peak flow).

\begin{tabular}{|c|c|c|c|c|c|c|}
\hline \multirow[t]{4}{*}{ Basin } & \multirow[t]{4}{*}{$Q_{\mathrm{obs}}$} & $Q_{\text {sim }}$ & \multicolumn{4}{|c|}{$Q_{\text {median }}$} \\
\hline & & FEST-WB & \multicolumn{4}{|c|}{ COSMO-LEPS } \\
\hline & & & (lead time 4) & (lead time 3 ) & (lead time 2) & (lead time 1$)$ \\
\hline & & $(120-98 \mathrm{~h})$ & (96-72h) & $(72-48 \mathrm{~h})$ & $(48-24 \mathrm{~h})$ & (48-24 h) \\
\hline Toce & 916 & 992 & 328 & 1028 & 1158 & 1841 \\
\hline Sesia & 2025 & 1685 & 656 & 1337 & 1213 & 2203 \\
\hline
\end{tabular}
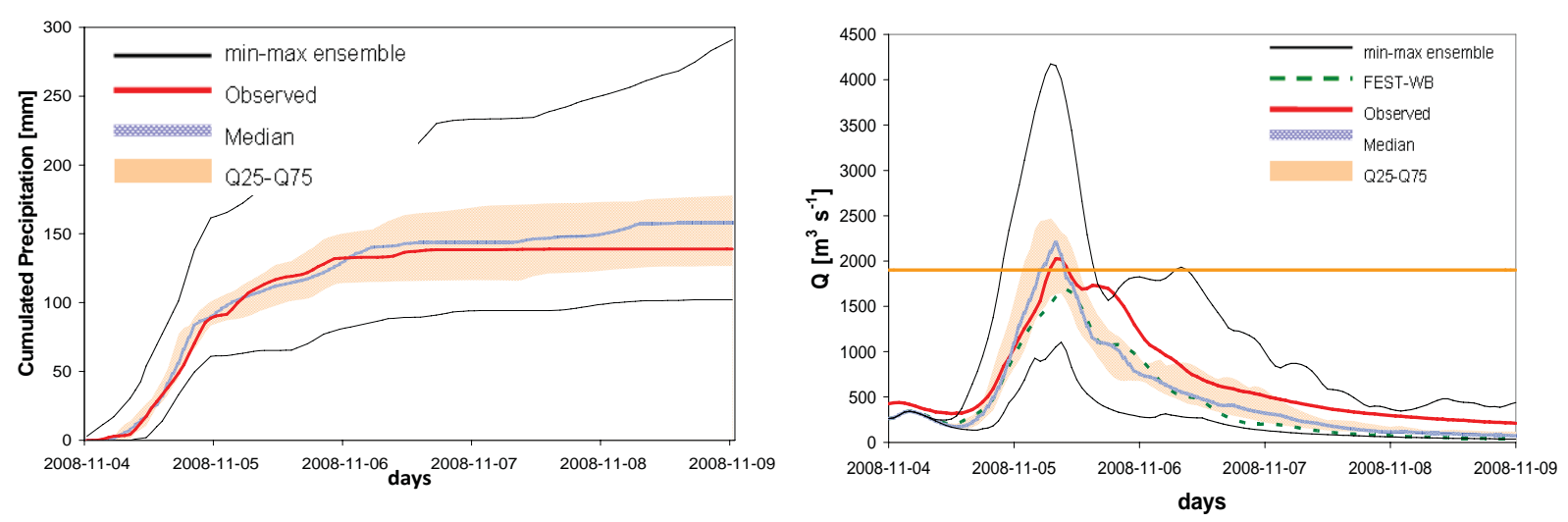

Fig. 3. Quantitative precipitation forecast, QPF, (left) of the COSMO-LEPS model in comparison to the mean cumulative observed precipitation (red line) over the Sesia Basin; the purple line shows the COSMO-LEPS median precipitation, the light orange shadows show the COSMO-LEPS 25th and 75th percentile precipitation and the black lines refer to the COSMO-LEPS envelope precipitation. The run started on 4 November 2008. QDF (right) of the FEST-WB model forced with observed data (green dashed line) and COSMO-LEPS meteorological data. In particular, the red line shows the observed discharge at Palestro, the purple line shows the ensemble median discharge, the light orange shadows show the ensemble 25 th and 75 th percentile discharge and the black lines refer to the ensemble envelope discharge. The run started on 4 November 2008. The horizontal orange line is the warning code 2 for the Sesia Basin.
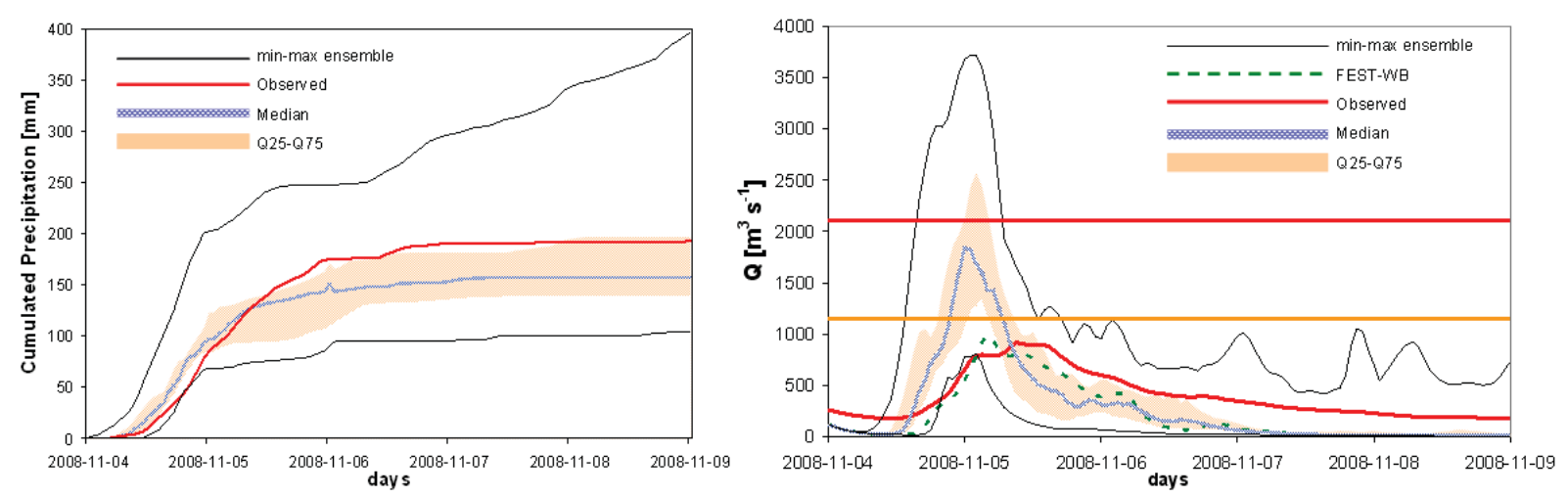

Fig. 4. QPF (left) of the COSMO-LEPS model in comparison to the mean cumulative observed precipitation (red line) over the Toce Basin; the purple line shows the COSMO-LEPS median precipitation, the light orange shadows show the COSMO-LEPS 25th and 75th percentile precipitation and the black lines refer to the COSMO-LEPS envelope precipitation. The run started on 4 November 2008. QDF (right) of the FEST-WB model forced with observed data (green dashed line) and COSMO-LEPS meteorological data. In particular, the red line shows the observed discharge at Candoglia, the purple line shows the ensemble median discharge, the light orange shadows show the ensemble 25th and 75th percentile discharge and the black lines refer to the ensemble envelope discharge. The run started on 4 November 2008 . The horizontal orange and red lines are the warning codes 2 and 3, respectively, for the Toce Basin. 


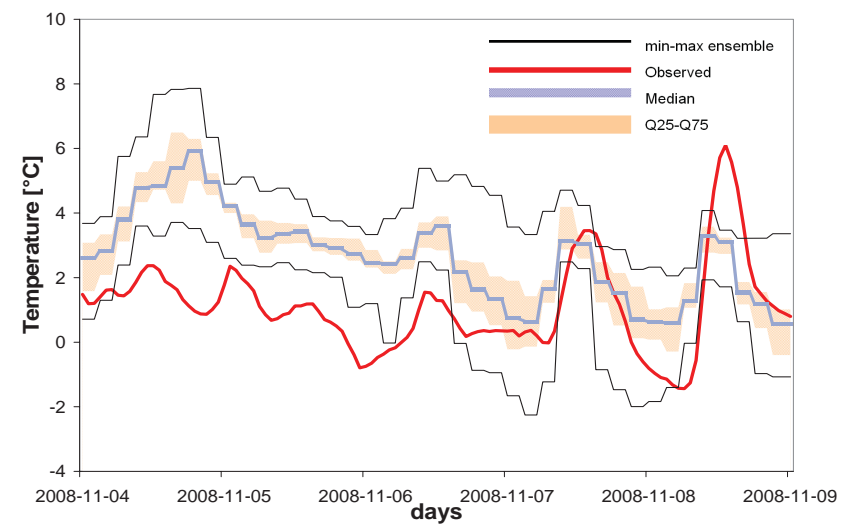

Fig. 5. Forecasted temperature by the COSMO-LEPS model, in comparison with the observed value (red line); the purple line shows the COSMO-LEPS median temperature, the light orange shadows show the COSMO-LEPS 25 th and 75 th percentile temperature and the black lines refer to the COSMO-LEPS envelope temperature. Values are referred to as the mean area temperatures. The run started on 4 November 2008.

- $f\left(P^{0}, T^{0}\right)=$ the maximum discharge value of hydrological model simulation forced with both $P$ and $T$ fixed at the observed data;

- $f\left(P^{1}, T^{1}\right)=$ the maximum discharge value of the ensemble median of hydrological model simulation forced with both $P$ and $T$ at the values forecasted by the COSMO-LEPS model.

Then, by the factor separation method extended to factor groups (Sobol', 1993; Borgonovo and Peccati, 2011), one can write

$\Delta f=\Delta f_{P}+\Delta f_{T}+\Delta f_{P, T}$,

where

- $\Delta f_{P}$ is the difference between the FEST-WB simulation (referred to as $S_{0}$ ), forced with all observed values, and the FEST-WB simulation forced with the observed temperature field, and the forecasted precipitation values of the COSMO-LEPS model; this latter simulation is referred to as $S_{1}$;

- $\Delta f_{T}$ is the difference between the FEST-WB simulation (referred to as $S_{0}$ ), forced with all observed values, and the FEST-WB simulation forced with the observed precipitation field, but with the forecasted temperature values of the COSMO-LEPS model; this latter simulation is referred to as $S_{2}$;

- $\Delta f_{P, T}$ is the difference between the FEST-WB simulation (referred to as $S_{0}$ ), forced with all observed values, and the FEST-WB simulation forced with both the forecasted precipitation and temperature values of the COSMO-LEPS model; this latter simulation is referred to as $S_{3}$.

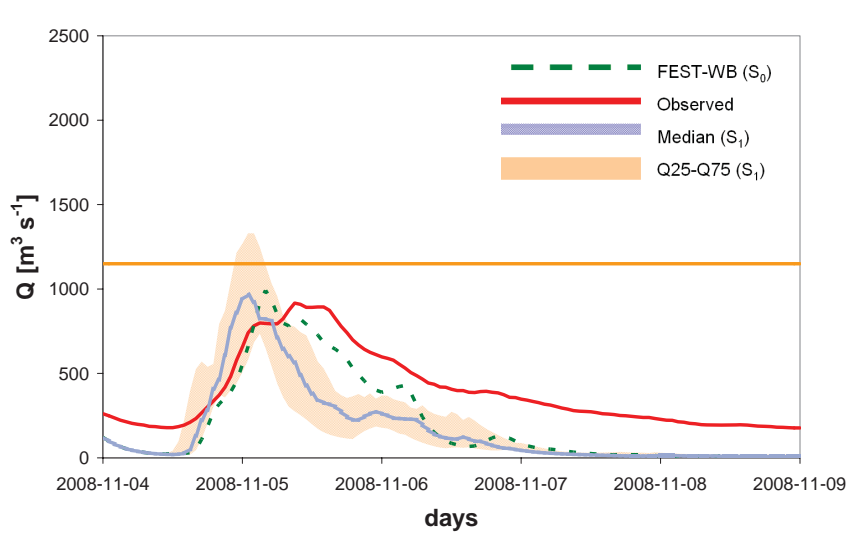

Fig. 6. QDF of the FEST-WB simulation $\left(S_{1}\right)$ forced with observed temperature field and forecasted precipitation by the COSMOLEPS model (blue line). The red line shows the observed discharge at Candoglia and the green dashed line shows the simulated discharge by the FEST-WB $\left(S_{0}\right)$, forced with observed data; the hydrological simulation was started on 4 November 2008. The horizontal orange line is the warning codes 2 for the Toce Basin.

First of all, as we have already seen in Fig. 4, we point out that the simulated discharge by the FEST-WB model, forced with all observed field values (precipitation, temperature, humidity and solar radiation) is very similar in terms of peak amount to the measured discharge.

Thus, the first two steps of the decomposition involve individual changes in "precipitation" and "temperature" to compare the discharge differences; in particular, we alternated the observed precipitation and temperature fields with the forecasted fields. The humidity and solar radiation field were not changed in this sensitivity analysis; instead, their inputs were always implemented as observed data.

Figure 6 shows that no large differences exist between the two simulations $S_{0}$ and $S_{1}$ : i.e. putting the COSMO-LEPS precipitation field as input in the FEST-WB model and maintaining the other observed meteorological data (air temperature, relative humidity and solar radiation), the discharge difference $\Delta f_{P}$ between the ensemble median (blue line) and the FEST-WB (green dashed line) is only $-26 \mathrm{~m}^{3} \mathrm{~s}^{-1}$.

On the contrary for the simulation $S_{2}$ shown in Fig. 7, the ensemble median $Q_{\max }$ shows a remarkable difference of $686 \mathrm{~m}^{3} \mathrm{~s}^{-1}$ in comparison with $S_{0}$.

The simulation $S_{2}$ is the keystone in our analysis and it answers our proposed objectives. The discharge overestimation (ensemble median value of $1678 \mathrm{~m}^{3} \mathrm{~s}^{-1}$ ), exceeding alert code 2, can only be attributed to an error of the COSMOLEPS forecasted temperature (about $3{ }^{\circ} \mathrm{C}$ higher than the observed temperature; see Fig. 5) because it was the only changed variable in this new simulation scenario.

Finally, we considered both the forecasted temperature and precipitation fields by the COSMO-LEPS model in order to understand the simultaneous interaction of effects of the inputted changes; the latter simulation is referred to as $S_{3}$. 


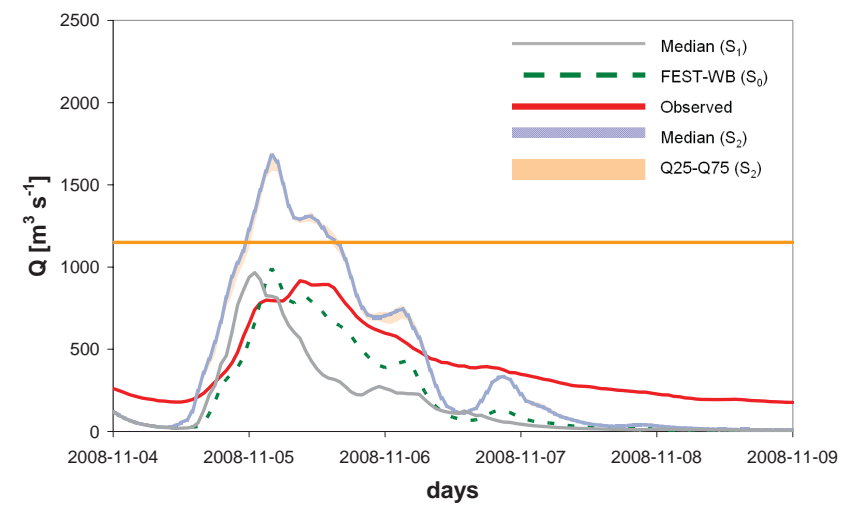

Fig. 7. QDF of the FEST-WB simulation $\left(S_{2}\right)$ forced with observed precipitation field and forecasted temperatures by the COSMOLEPS model (blue line). The red line shows the observed discharge at Candoglia and the green dashed line shows the simulated discharge on the FEST-WB, forced with observed data $\left(S_{0}\right)$. The grey line illustrates the ensemble median of the simulation $S_{1}$, as a comparison with the new simulation $\left(S_{2}\right)$. The hydrological simulation was initialized on $4+$ November 2008. The horizontal orange line is warning code 2 for the Toce Basin.

Figure 8 shows an increase in the peak discharge: the ensemble median reaches a value of $1841 \mathrm{~m}^{3} \mathrm{~s}^{-1}$ (grey dashed line), with a difference of about $849 \mathrm{~m}^{3} \mathrm{~s}^{-1}(\Delta f)$ in comparison with the FEST-WB simulation $\left(S_{0}\right)$, forced with all observed fields. By Eq. (5) the interaction effect $\left(\Delta f_{P, T}\right)$ is equal to $+189 \mathrm{~m}^{3} \mathrm{~s}^{-1}$, showing that the forecasted discharge error cannot be explained only by individual effects; instead, interactions play a relevant role. The magnitude of this term is non-negligible in comparison with the other effects, signalling that the response of the hydrological model is structurally non-additive.

\subsection{Effects of temperature on the peak discharge}

Once assessed that the false alarm in discharge forecast over the Toce Basin mainly depends on temperature errors, this overestimation in terms of peak discharge over both the analysed basins was quantified performing simulations, using the observed precipitation data, but changing the temperature input field (all the other input fields were unchanged).

In fact, by raising all observed temperature data in the subject area by $0.5,1.0,1.5,2.0$, and $2.5^{\circ} \mathrm{C}$, five temperature fields were created as input into the hydrological FESTWB model in order to obtain five corresponding simulations. This enables us to quantify the extent to which temperature errors can influence the discharge outputs over these two watersheds without COSMO-LEPS forecasts. Increasing the temperature field by an interval of $0.5^{\circ} \mathrm{C}$ means raising the snow line about $100 \mathrm{~m}$ at a time for a snow line which was located around 1700-2100 m a.s.l. over mountain basins for this event. Therefore, correlating this increase in temperature with the ipsographic curve, we were able to understand

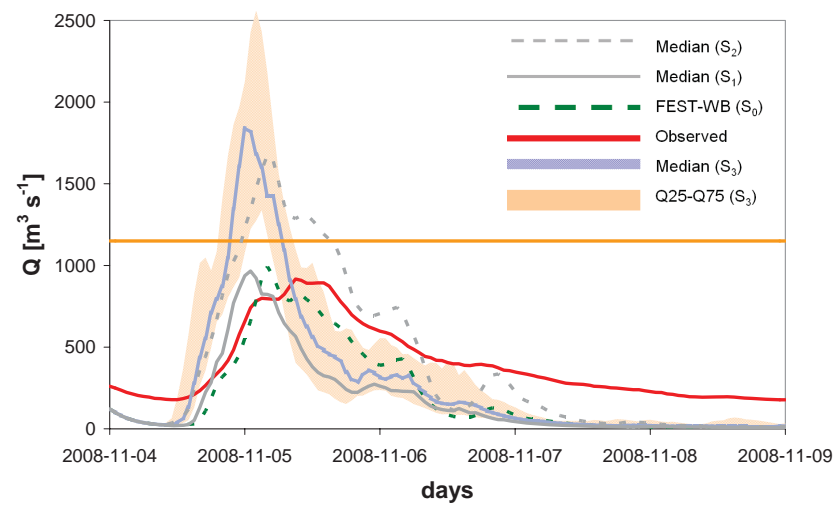

Fig. 8. QDF of the FEST-WB simulation $\left(S_{3}\right)$ forced with both forecasted precipitation and temperature fields by the COSMO-LEPS model (blue line). The red line shows the observed discharge at Candoglia and the green dashed line shows the simulated discharge on the FEST-WB $\left(S_{0}\right)$, forced with observed data. The grey line shows the ensemble median of the $S_{1}$ simulation, the grey dashed line illustrates the $S_{2}$ simulation; the hydrological simulation was initialized on 4 November 2008. The horizontal orange line is warning code 2 for the Toce Basin.

which is the contributing area in snow melt dynamics over the Toce and Sesia basins.

The dashed coloured lines in Fig. 9 correlate the percentage of contributing area to runoff with different snow lines, related to our modified temperature fields (from $0.5^{\circ} \mathrm{C}$ up to $2.5^{\circ} \mathrm{C}$ ). Since the observed snow line between 4 and 5 November was approximately at 1900-2000 m a.s.l. (green dashed line), about $60 \%$ of the basin area is subject to liquid precipitation (rain) over the Toce and greater than $90 \%$ over the Sesia Basin were involved.

In particular, raising the $0{ }^{\circ} \mathrm{C}$ line over the Toce catchment (Fig. 9-left), this means that the snowfall line also increases, and therefore the drainage area becomes greater. In fact, a rise of $2.5^{\circ} \mathrm{C}$ brings the snow line to about $2400 \mathrm{~m}$ a.s.1. with a contributing area greater then $85 \%$ that in terms of discharge simulations brings more liquid water reaching the basin gauging station faster.

On the contrary, with a totally different ipsographic curve over the Sesia Basin, a rise in the temperature and therefore the snow line, no relevant differences are shown in peak discharges (Fig. 9 - right); in fact, the contributing area does not change significantly (less than $10 \%$ ).

In Fig. 10, five different discharge simulations are shown for the corresponding five selected temperature increases over the Toce and Sesia catchments.

As expected, a rise in temperature over the Toce Basin implies an increase of discharge values which was not found over the Sesia, where a discharge underestimation still remains due to the hydrological model performance. In Fig. 11 the percentage overestimation of the FEST-WB simulations forced with the five modified temperature fields is shown both for the Toce and Sesia basins. 

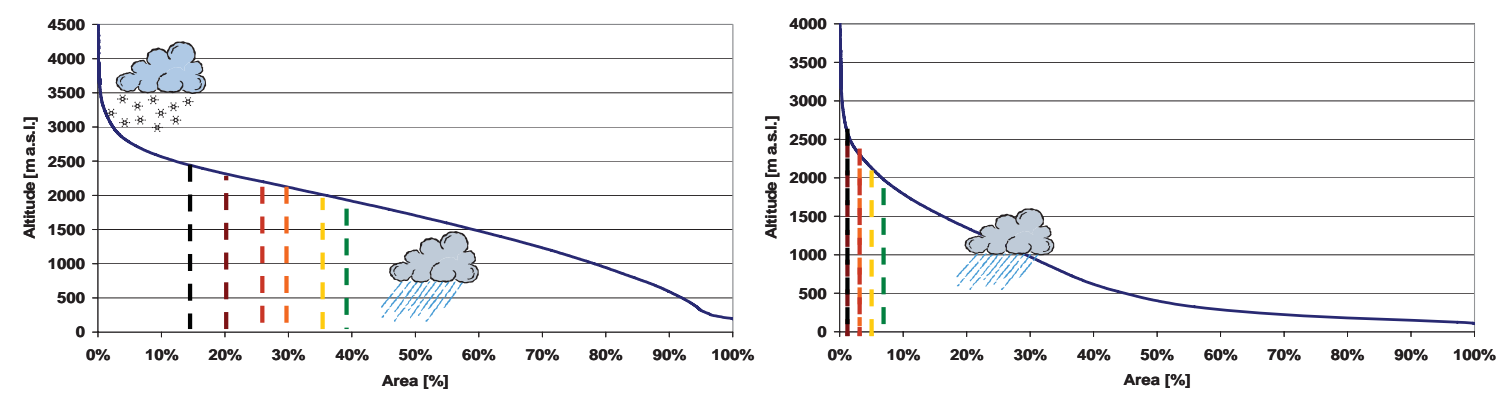

Fig. 9. Ipsographic curve for the Toce (left) and Sesia (right) watershed. The green dashed line refers to the actual snow line located at about 1900-2000 m a.s.1., while the other coloured dashed lines refer to the rising of the snow line due to an artificial increase in temperature at $0.5^{\circ} \mathrm{C}$ intervals. The plots correlate the total contributing area to the basin altitude. In standard atmosphere conditions the temperature lapse rate is $0.65^{\circ} \mathrm{C}$ per $100 \mathrm{~m}$, which is the same value used in the FEST-WB model.
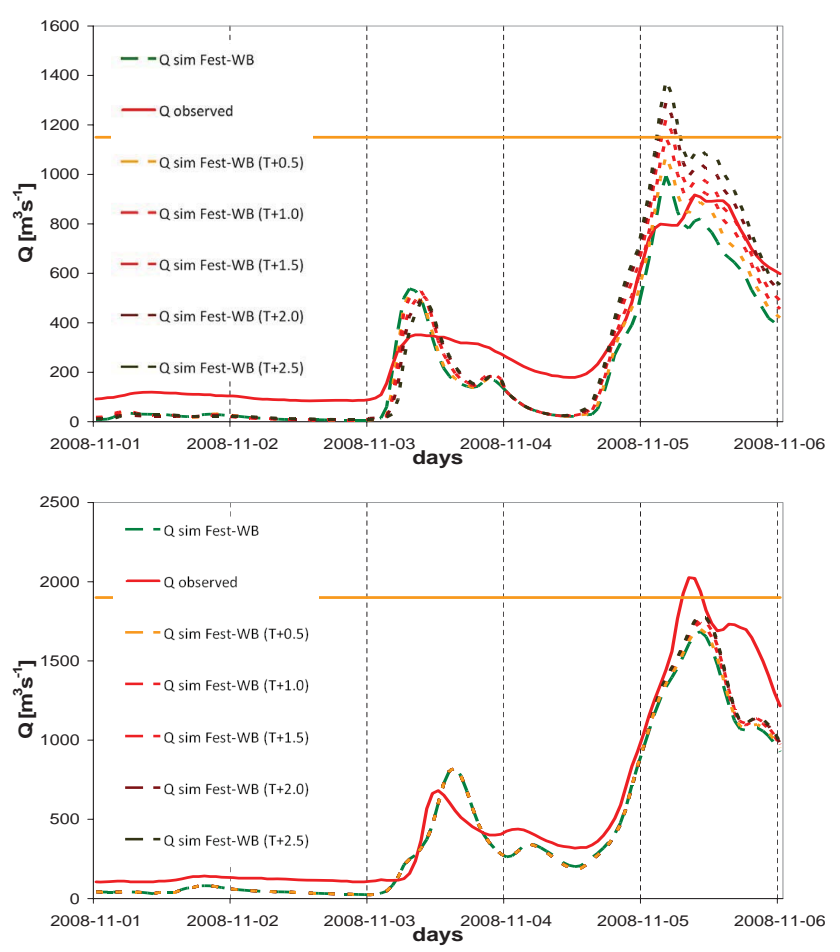

Fig. 10. Discharge simulations over the Toce (above) and Sesia (below) basins, with the modified temperature field as input into the FEST-WB model initialized on the 1 November 2008. The measured discharges at Candoglia and Palestro are highlighted in red, the FEST-WB simulations forced with observed data are shown by the green lines, while coloured dashed lines refer to discharge simulation by the FEST-WB model forced with increased temperature at $0.5^{\circ} \mathrm{C}$ intervals. In this case we launched the simulation on 1 November to show the entire simulation for the event.

The horizontal orange line is warning code 2 for the Toce (above) and Sesia (below) basins.

With an increase in temperature from $0.5^{\circ} \mathrm{C}$ up to $2.5^{\circ} \mathrm{C}$ over the Toce Basin, the snow line was raised by approximately $500 \mathrm{~m}$, with a significant difference in terms of water runoff for the 5 November peak. For instance, the maximum discharge $\left(1378 \mathrm{~m}^{3} \mathrm{~s}^{-1}\right)$ simulated with a modified tempera-

\begin{tabular}{|c|c|c|c|}
\hline \multicolumn{2}{|c|}{ Evaluation Discharge error } & \multicolumn{2}{|c|}{ Evaluation Discharge error } \\
\hline$+0.5^{\circ} \mathrm{C}$ & $------\quad+8 \%$ & $+0.5^{\circ} \mathrm{C}$ & $------+1 \%$ \\
\hline$+1.0^{\circ} \mathrm{C}$ & $------+16 \%$ & $+1.0^{\circ} \mathrm{C}$ & $------\quad+3 \%$ \\
\hline$+1.5^{\circ} \mathrm{C}$ & $------+23 \%$ & $+1.5^{\circ} \mathrm{C}$ & $------\quad+5 \%$ \\
\hline$+2.0^{\circ} \mathrm{C}$ & $-----+30 \%$ & $+2.0^{\circ} \mathrm{C}$ & $-----+5.8 \%$ \\
\hline$+2.5^{\circ} \mathrm{C}$ & $-----+39 \%$ & $+2.5^{\circ} \mathrm{C}$ & $-----+6.1 \%$ \\
\hline $\mathrm{T}\left[{ }^{\circ} \mathrm{C}\right]$ & $\mathrm{E}$ & $\mathrm{T}\left[{ }^{\circ} \mathrm{C}\right]$ & $\mathrm{Er}$ \\
\hline
\end{tabular}

Fig. 11. Evaluation discharge errors based on a rise in temperature over the Toce (left) and Sesia (right) basins. The percentage of errors refers to the main peak discharge which occurred on 5 November 2008. The legend of coloured dashed lines of the snow line rise is the same shown in Fig. 10.

ture field of $2.5^{\circ} \mathrm{C}$ is higher by $39 \%$ in comparison with the discharge simulated by the FEST-WB model forced with observed data. On the contrary, over the Sesia Basin the rise in the snowfall line does not imply any differences in discharge error; regardless of whether the $0^{\circ} \mathrm{C}$ line is at about $1900 \mathrm{~m}$ or at about $2500 \mathrm{~m}$ a.s.l., the precipitation remained in liquid form in almost the entire basin, and the evaluated error variation was only $5 \%$.

In order to investigate the influence of temperature on discharge simulations in depth, the SWE (snow water equivalent) calculated with modified temperature values by the FEST-WB model is shown also in Fig. 12.

An increase in temperature causes a decrease of SWE because there is less snow to be melted. Over the Toce Basin, with a rise in the temperature field of $2.5^{\circ} \mathrm{C}$, there is a difference of about $30 \mathrm{~mm}$ as mean basin value (Fig. 12 - left). On the contrary, as can be seen in Fig. 12 (right), there is no difference in the SWE with the modified temperature field over the Sesia basin. This further demonstrates that the impact of temperature error in the meteorological model forecasts strongly depends on the basin ipsographic curve and therefore on the total contributing area during precipitation. This aspect is particularly relevant in autumn, when the first significant snowfalls occur over Alpine watersheds whose soil is not yet covered by snow. These conditions may favour floods (like in November 1994 and October 2000). 

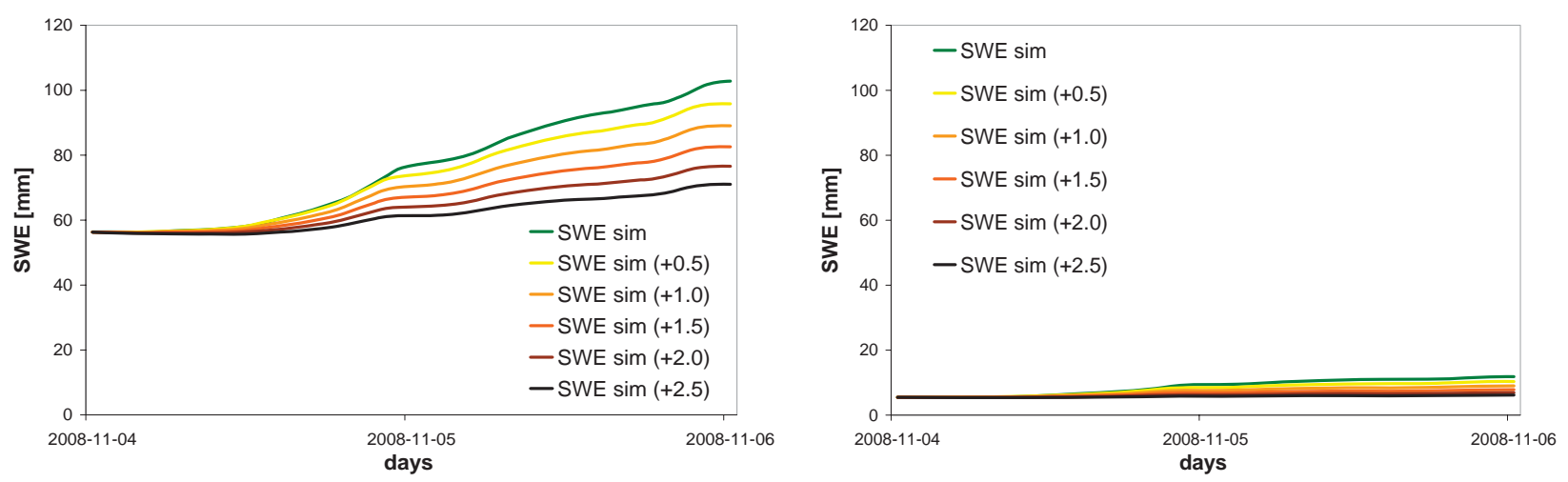

Fig. 12. SWE simulations over the Toce (left) and Sesia (right) basins. The snow water equivalents simulated by the FEST-WB forced with all observed data are shown by the green lines, while coloured dashed lines refer to discharge simulations by the FEST-WB model forced with modified temperature fields at $0.5^{\circ} \mathrm{C}$ intervals. Data are shown in $\mathrm{mm}$ on the y-axis; the scale plot is the same for the two basins to highlight the SWE differences. The figure shows a zoom on 4 and 5 November when heavy rainfall over the north-western part of the Piedmont region occurred.

\section{Conclusions}

In this study attention was focused on the ability of a coupled meteorological-hydrological forecasting system to predict discharges at different lead times, and on the critical impact of temperature in determining the partitioning of precipitation in solid (snow) and liquid (rainfall) phase and consequently on the discharge peaks. We analysed an event which occurred in November 2008 to better understand how the forecast temperature error can affect snow dynamics during a severe precipitation event with a crucial snow line over two mountain basins - an issue that has not yet been investigated in depth in scientific literature.

We have seen that precipitation is not the only atmospheric forcing, but temperature forecast has to be taken into account in discharge prediction, above all over mountainous areas, where weather forecasts are complicated by orographic effects.

Depending on the basin ipsographic curve and snow line, a temperature forecast error can have a relevant influence on the river discharge prediction with huge under/overestimations with consequent false or miss alarms in hydrological forecasts.

In particular, we describe in detail a hydrological process for a real occurred case study of a warm bias during a hydrometeorological event over two Alpine basins.

We have introduced a sensitivity analysis method for assessing the results and for demonstrating the problem of a warm bias. By this method we were able to partition the error in the peak discharge forecast to individual effects of precipitation and temperature and to their interaction. We have quantified how the QDF is influenced by temperature related to the ipsographic curve of the Toce and Sesia basins, and therefore to the percentage of the area that contributes liquid water (rain) in the two watersheds. We have seen in this event how a warm bias can have a big impact on hydrological forecasts over the Toce Basin, but not over the Sesia, due to a different relationship between the snow line and the ispographic curve of the basins.

The knowledge of the forecasted snow line is absolutely fundamental during alert conditions.

Before an event the possibility to have a different set of hydrological forecasts obtained by perturbing forecasted temperature fields allows insight into how much forecasted temperature errors can affect peak discharge forecasts.

A future aspect to consider will be a comparison of discharge forecasts calculated with two different rain/snow partitioning algorithms: one computed by the hydrological model and the other coming from the weather model itself.

Finally, it is important to state that in this paper we do not claim to give general rules because a large number of cases study have to be considered. However, we have inspected another source of uncertainty which lies behind a hydrometeorological forecast that must be taken into account in real-time forecast systems, especially in cold seasons over mountain basins.

Acknowledgements. This work was partially supported by Dote Ricerca Applicata, funded by Regione Lombardia.

E dited by: L. Garrote

Reviewed by: three anonymous referees

\section{References}

Amengual, A., Diomede, T., Marsigli, C., Martín, A., Morgillo, A., Romero, R., Papetti, P., and Alonso, S.: A hydrometeorological model intercomparison as a tool to quantify the forecast uncertainty in a medium size basin, Nat. Hazards Earth Syst. Sci., 8, 819-838, doi:10.5194/nhess-8-819-2008, 2008.

Arpagaus, M., Rotach, M., Ambrosetti, P., Ament, F., Appenzeller, C., Bauer, H. S., Bouttier, F., Buzzi, A., Corazza, M., Davolio, S., Denhard, M., Dorninger, M., Fontannaz, L., Frick, J., Fundel, F., Germann, U., Gorgas, T., Grossi, G., Hegg, C., Hering, 
A., Jaun, S., Keil, C., Liniger, M., Marsigli, C., McTaggartCowan, R., Montani, A., Mylne, K., Ranzi, R., Richard, E., Rossa, A., Santos-Muñoz, D., Schär, C., Seity, Y., Staudinger, M., Stoll, M., Vogt, S., Volkert, H., Walser, A., Wang, Y., Werhahn, J., Wulfmeyer, V., Wunram, C., and Zappa, M.: MAP DPHASE: Demonstrating forecast capabilities for flood events in the Alpine region, Veröffentlichungen der MeteoSchweiz, Scientific Reports, 78, 75 pp., ISSN 1422-1381, 2009.

Bacchi, B. and Ranzi, R.: Hydrological and meteorological aspects of floods in the Alps: an overview, Hydrol. Earth Syst. Sci., 7, 785-798, doi:10.5194/hess-7-785-2003, 2003.

Bartholmes, J. C., Thielen, J., Ramos, M. H., and Gentilini, S.: The european flood alert system EFAS - Part 2: Statistical skill assessment of probabilistic and deterministic operational forecasts, Hydrol. Earth Syst. Sci., 13, 141-153, doi:10.5194/hess-13-1412009, 2009.

Bocchiola, D., De Michele, C., and Rosso, R.: Review of recent advances in index flood estimation, Hydrol. Earth Syst. Sci., 7, 283-296, doi:10.5194/hess-7-283-2003, 2003.

Borgonovo, E.: Sensitivity analysis with finite changes: An application to modified EOQ models, Eur. J. Oper. Res., 200, 127-138, doi:10.1016/j.ejor.2008.12.025, 2010.

Borgonovo, E. and Peccati, L.: Managerial Insights from Service Industry Models: a new scenario decomposition method, Ann. Oper. Res., 185, 161-179, doi:10.1007/s10479-009-06171, 2011.

Brath, A. and Burlando, P.: Prospettive d'impiego di previsioni di pioggia nei sistemi di preannuncio di piena, Atti XXI Convegno idraulica e costruzioni idrauliche, L'Aquila, 5-8 Settembre 1988, I, 29-44, (U.O. 1.08), 1988 (in Italian).

Cloke, H. L. and Pappenberger, F.: Ensemble Flood Forecasting: a review, J. Hydrol., 375, 613-626, doi:10.1016/j.jhydrol.2009.06.005, 2009.

Corbari, C., Ravazzani, G., Martinelli, J., and Mancini, M.: Elevation based correction of snow coverage retrieved from satellite images to improve model calibration, Hydrol. Earth Syst. Sci., 13, 639-649, doi:10.5194/hess-13-639-2009, 2009.

Efron, B. and Stein, C.: The Jackknife Estimate of Variance, Ann. Stat., 9, 586-596, 1981.

Gouweleeuw, B. T., Thielen, J., Franchello, G., De Roo, A. P. J., and Buizza, R.: Flood forecasting using medium-range probabilistic weather prediction, Hydrol. Earth Syst. Sci., 9, 365-380, doi:10.5194/hess-9-365-2005, 2005.

He, Y., Wetterhall, F., Cloke, H. L., Pappenberger, F., Wilson, M., Freer, J., and McGregor, G.: Tracking the uncertainty in flood alerts driven by grand ensemble weather predictions, Meteorol. Appl., 16, 91-101, doi:10.1002/met.132, 2009.

Jaun, S.: Towards operational probabilistic runoff forecasts. Assessment of uncertainties within a coupled hydrometeorological modelling system, Ph.D. thesis, Eidgenössische Technische Hochschule (ETH) Zurich, doi:10.3929/ethz-a-005788939, 2008.

Jaun, S., Ahrens, B., Walser, A., Ewen, T., and Schär, C.: A probabilistic view on the August 2005 floods in the upper Rhine catchment, Nat. Hazards Earth Syst. Sci., 8, 281-291, doi:10.5194/nhess-8-281-2008, 2008.

Krzysztofowicz, R.: Bayesian theory of probabilistic forecasting via deterministic hydrologic model, Water Resour. Res., 35, 27392750, doi:10.1029/1999WR900099, 1999.
Krzysztofowicz, R.: The case for probabilistic forecasting in hydrology, J. Hydrol., 249, 2-9, doi:10.1016/S00221694(01)00420-6, 2001.

Little, J. D. C.: Models and managers: the concept of a decision calculus, Management Science, Application Series, 16, B466B485, doi:10.1287/mnsc.1040.0267, 1970.

Mancini, M.: La modellazione distribuita della risposta idrologica: effetti della variabilità spaziale e della scala di rappresentazione del fenomeno dell'assorbimento, Tesi di dottorato, Politecnico di Milano, 1990 (in Italian).

Marsigli, C., Boccanera, F., Montani, A., and Paccagnella, T.: The COSMO-LEPS mesoscale ensemble system: validation of the methodology and verification, Nonlin. Processes Geophys., 12, 527-536, doi:10.5194/npg-12-527-2005, 2005.

Martinec, J. and Rango, A.: Parameter values for snowmelt runoff modelling, J. Hydrol., 84, 197-219, doi:10.1016/00221694(86)90123-X, 1986.

Montaldo, N., Toninelli, V., Albertson, J. D., Mancini, M., and Troch, P. A.: The effect of background hydrometeorological conditions on the sensitivity of evapotranspiration to model parameters: analysis with measurements from an Italian alpine catchment, Hydrol. Earth Syst. Sci., 7, 848-861, doi:10.5194/hess-7848-2003, 2003.

Montaldo, N., Ravazzani, G., and Mancini, M.: On the prediction of the Toce alpine basin floods with distributed hydrologic models, Hydrol. Process., 21, 608-621, doi:10.1002/hyp.6260, 2007.

Montani, A., Capaldo, M., Cesari, D., Marsigli, C., Modiglioni, U., Nerozzi, F., Paccagnella, T., Patruno, P., and Ribaldi, S.: Operational limited-area ensemble forecasts based on the Lokal Modell, ECMWF Newsletter, 98, 2-7, 2003.

Montani, A., Cesari, D., Marsigli, C., and Paccagnella, T.: Seven years of activity in the field of mesoscale ensemble forecasting by the COSMO-LEPS system: main achievements and open challenges, Tellus A, 63, 605-624, doi:10.1111/j.16000870.2010.00499.x, 2011.

Munich Reinsurance Company (Munich Re): Topics Geo natural catastrophes 2010: analyses, assessments, positions, Munich Re, München, Germany, 52 pp., 2011.

Pappenberger, F., Beven, K. J., Hunter, N. M., Bates, P. D., Gouweleeuw, B. T., Thielen, J., and de Roo, A. P. J.: Cascading model uncertainty from medium range weather forecasts (10 days) through a rainfall-runoff model to flood inundation predictions within the European Flood Forecasting System (EFFS), Hydrol. Earth Syst. Sci., 9, 381-393, doi:10.5194/hess-9-3812005, 2005.

Pianosi, F. and Ravazzani, G.: Assessing rainfall-runoff models for the management of Lake Verbano, Hydrol. Process., 24, 31953205, doi:10.1002/hyp.7745, 2010.

Rabitz, H. and Alis, Ö. F.: General foundations of highdimensional model representations, J. Math. Chem., 25, 197233, doi:10.1023/A:1019188517934, 1999.

Rabuffetti, D. and Milelli, M.: The hydro-meteorological chain in Piemonte region, North Western Italy - analysis of the HYDROPTIMET test cases, Nat. Hazards Earth Syst. Sci., 5, 845852, doi:10.5194/nhess-5-845-2005, 2005.

Rabuffetti, D., Salandin, A., and Cremonini, R.: Hydrological modelling of snow cover in the large upper Po river basin: winter 2004 results and validation with snow cover estimation from satellite, Geo-Environment and Landscape Evolution II, 2006. 
Rabuffetti, D., Ravazzani, G., Corbari, C., and Mancini, M.: Verification of operational Quantitative Discharge Forecast (QDF) for a regional warning system - the AMPHORE case studies in the upper Po River, Nat. Hazards Earth Syst. Sci., 8, 161-173, doi:10.5194/nhess-8-161-2008, 2008.

Rabuffetti, D., Ravazzani, G., Barbero, S., and Mancini, M.: Operational flood-forecasting in the Piemonte region - development and verification of a fully distributed physically-oriented hydrological model, Adv. Geosci., 17, 111-117, doi:10.5194/adgeo17-111-2009, 2009.

Ramos, M. H., Bartholmes, J., and Thielen, J.: Development of decision support products based on ensemble weather forecasts in the European Flood Alert System, Atmos. Sci. Lett., 8, 113-119, doi:10.1002/asl.161, 2007.

Ranzi, R., Bacchi, B., and Grossi, G.: Runoff measurements and hydrological modelling for the estimation of rainfall volumes in an alpine basin, Q. J. Roy. Meteor. Soc., 129B, 653-672, doi:10.1256/qj.02.60, 2003

Ranzi, R., Zappa, M., and Bacchi, B.: Hydrological aspects of the Mesoscale Alpine Programme: findings from field experiments and simulations, Q. J. Roy. Meteor. Soc., 133B, 867-880, doi:10.1002/qj.68, 2007.

Ranzi, R., Bacchi, B., Ceppi, A., Cislaghi, M., Ehret, U., Jaun, S., Marx, A., Hegg, C., and Zappa, M.: Real-time demonstration of hydrological ensemble forecasts in MAP D-PHASE, La Houille Blanche, 5, 95-104, 2009.

Ravazzani, G.: MOSAICO, a library for raster based hydrological applications, Comput. Geosci., 51, 1-6, doi:10.1016/j.cageo.2012.08.007, 2013.

Ravazzani, G., Mancini, M., Giudici, I., and Amadio, P.: Effects of soil moisture parameterization on a real-time flood forecasting system based on rainfall thresholds, in: Quantification and Reduction of Predictive Uncertainty for Sustainable Water Resources Management, Proc. Symposium HS 2004 at IUGG 2007, Perugia, July 2007, IAHS Publ., 313, 407-416, 2007.

Ravazzani, G., Rabuffetti, D., Corbari, C., Ceppi, A., and Mancini, M.: Testing FEST-WB, a continuous distributed model for operational quantitative discharge forecast in the upper Po river, Proceedings of the AMHY-FRIEND International Workshop on Hydrological Extremes, University of Calabria, Cosenza (Italy), 10-12 July 2008, 2010.

Ravazzani, G., Rametta, D., and Mancini, M.: Macroscopic Cellular Automata for groundwater modelling: a first approach, Environ. Modell. Softw., 26, 634-643, doi:10.1016/j.envsoft.2010.11.011, 2011.

Rossa, A., Haase, G., Keil, C., Alberoni, P., Ballard, S., Bech, J., Germann, U., Pfeifer, M., and Salonen, K.: Propagation of uncertainty from observing systems into NWP: COST-731 Working Group 1, Atmos. Sci. Lett., 11, 145-152, doi:10.1002/asl.274, 2010.

Rotach, M. W., Ambrosetti, P., Ament, F., Appenzeller, C., Arpagaus, M., Bauer, H. S., Behrendt, A., Bouttier, F., Buzzi, A., Corrazza, M., Davolio, S., Denhard, M., Dorninger, M., Fontannaz, L., Frick, J., Fundel, F., Germann, U., Gorgas, T., Hegg, C., Hering, A., Keil, C., Liniger, M. A., Marsigli, C., McTaggart-Cowan, R., Montani, A., Mylne, K., Ranzi, R., Richard, E., Rossa, A., Santos-Muñoz, D., Schär, C., Seity, Y., Staudinger, M., Stoll, M., Volkert, H., Walser, A., Wang, Y., Wulfmeyer, V., and Zappa, M.: MAP D-PHASE: Real-time Demonstration of Weather Forecast
Quality in the Alpine Region, B. Am. Meteorol. Soc., 90, 13211336, doi:10.1175/2009BAMS2776.1, 2009.

Schaake, J., Franz, K., Bradley, A., and Buizza, R.: The Hydrologic Ensemble Prediction EXperiment (HEPEX), Hydrol. Earth Syst. Sci. Discuss., 3, 3321-3332, doi:10.5194/hessd-3-33212006, 2006.

Serban, P. and Askew, A. J.: Hydrological forecasting and updating procedures, in: Hydrology for the Water Management of Large River Basins, edited by: van de Ven, F. H. M., Gutknecht, D., Loucks, D. P., and Salewicz, K. A., Proc. Vienna Symp., August 1991, IAHS Press, Wallingford, UK, IAHS Publ, 201, 357-367, 1991.

Sobol', I. M.: Sensitivity estimates for nonlinear mathematical models, Matem. Modelirovanie, 2, 112-118, 1990 (in Russian), English Transl.: MMCE, 1, 407-414, 1993.

Stein, U. and Alpert, P.: Factor Separation in Numerical Simulation, J. Atmos. Sci., 50, 2107-2115, 1983.

Tarboton, D. G., Chowdhury, T. G., and Jackson, T. H.: A Spatially Distributed Energy Balance Snowmelt Model, Utah Water Research Laboratory, Reports, Paper 60, 1994.

Thielen, J., Schaake, J., Hartman, R., and Buizza, R.: Aims, challenges and progress of the Hydrological Ensemble Prediction Experiment (HEPEX) following the third HEPEX workshop held in Stresa 27 to 29 June 2007, Atmos. Sci. Lett., 9, 29-35, doi:10.1002/asl.168, 2008.

Thielen, J., Bartholmes, J., Ramos, M.-H., and de Roo, A.: The European Flood Alert System - Part 1: Concept and development, Hydrol. Earth Syst. Sci., 13, 125-140, doi:10.5194/hess-13-1252009, 2009a.

Thielen, J., Bogner, K., Pappenberger, F., Kalas, M., Del Medico, M., and de Roo, A.: Monthly-medium and short-range flood warning: testing the limits of predictability, Meteorol. Appl., 16, 77-90, doi:10.1002/met.140, 2009b.

Verbunt, M., Walser, A., Gurtz, J., Montani, A., and Schär, C.: Probabilistic Flood Forecasting with a Limited-Area Ensemble Prediction System: Selected Case Studies, J. Hydrometeorol., 8, 897-909, doi:10.1175/JHM594.1, 2007.

Voronoi, G.: Nouvelles applications des paramètres continus à la théorie des formes quadratiques. J. Reine Angew. Math., 133, 97-178, 1907.

Weingartner, R., Barben, M., and Spreafico, M.: Floods in Mountain Areas - an Overview Based on Examples from Switzerland, J. Hydrol., 282, 10-23, 2003.

Westrick, K. J. and Mass, C. F.: An evaluation of a high-resolution hydrometeorological modeling system for prediction of a coolseason flood event in a coastal mountainous watershed, J. Hydrometeorol., 2, 161-180, 2001.

Zappa, M., Rotach, M. W., Arpagaus, M., Dorninger, M., Hegg, C., Montani, A., Ranzi, R., Ament, F., Germann, U., Grossi, G., Jaun, S., Rossa, A., Vogt, S., Walser, A., Wehrhan, J., and Wunram, C.: MAP D-PHASE: real-time demonstration of hydrological ensemble prediction systems, Atmos. Sci. Lett., 2, 80-87, doi:10.1002/asl.183, 2008.

Zappa, M., Beven, K. J., Bruen, M., Cofino, A., Kok, K., Martin, E., Nurmi, P., Orfila, B., Roulin, E., Schröter, K., Seed, A., Stzurc, J., Vehviläinen, B., Germann, U., and Rossa, A.: Propagation of uncertainty from observing systems and NWP into hydrological models: COST-731 Working Group 2, Atmos. Sci. Lett., 2, 8391, doi:10.1002/asl.248, 2010. 